\title{
sciendo
}

\section{EFFECT OF HYBRID RYE AND MAIZE GRAIN PROCESSING ON RUMINAL AND POSTRUMINAL DIGESTIBILITY PARAMETERS*}

\author{
Patrycja Rajtar ${ }^{1}$, Paweł Górka1 ${ }^{1}$ Tomasz Schwarz ${ }^{2}$, Piotr Micek ${ }^{1}$ \\ ${ }^{1}$ Department of Animal Nutrition and Dietetics, \\ ${ }^{2}$ Department of Swine and Small Animal Breeding, \\ University of Agriculture in Kraków, al. Mickiewicza 24/28, 30-059 Kraków, Poland \\ Corresponding author: rzmicek@cyf-kr.edu.pl
}

\begin{abstract}
The aim of the study was to determine the effect of the method of fragmentation of hybrid rye and maize grain on digestibility parameters for ruminants. Varying degrees of fragmentation - none (whole grains; WG), crushed (CG) or ground to pass through a 4.0 (GG4.0) or $1.5 \mathrm{~mm}$ (GG1.5) screen - were estimated by the in sacco nylon bag technique, in vitro true digestibility (IVTD), and the in vitro gas production (GP) technique. WG, CG, GG4.0 and GG1.5 were categorized as none, slight, moderate and extensive fragmentation of the grain kernel, respectively. Three non-lactating cows fitted with ruminal and duodenal cannulas were used to determine the effective rumen degradability (ERD) and intestinal and total tract digestibility (ID and TTD, respectively) of dry matter (DM), crude protein (CP) and starch. IVTD was determined with an ANKOM Daisy" Incubator, and GP and in vitro organic matter digestibility were determined with an $\mathrm{ANKOM}^{\mathrm{RF}}$ Gas Production System. Dry matter, CP and starch of hybrid rye grain were rapidly degraded in the rumen, and this degradability as well as ID and TTD was only marginally affected by the method of kernel fragmentation; however, among the methods used, the ERD of GG4.0 rye was the lowest. On the other hand, the greater the degree of kernel fragmentation, the higher ERD, ID and TTD were obtained for the DM, CP and starch of maize grain. In summary, rye grain is more susceptible to fermentation in the rumen than maize grain, but the means of grain processing may alter the rate, extent and site of their digestion, particularly for maize grain.
\end{abstract}

Key words: cereal grain, hybrid rye, processing, in vitro technique, digestibility

Maize grain is one of the most popular cereal grains used in diets for ruminants. However, due to the relatively high prices of maize grain and some difficulties in maize cultivation (e.g. low resistance to drought and increasing difficulties in controlling pests), a search for alternatives to maize grain in ruminant nutrition is justi-

*This study was supported by funds from the National Centre for Research and Development (NCRD), ENERGYFEED grant, project No BIOSTRATEG2/297910/12/NCBR/2016. 
fied. Compared to maize, hybrid varieties of rye are resistant to disease and frost and are less often contaminated with mycotoxins (Grajewski et al., 2012). Furthermore, the yield potential of hybrid varieties of rye is higher and much more stable than that of open-pollinated varieties (Petr, 2005).

Compared with the starch of maize grain, rye grain starch is rapidly fermented in the rumen (Micek, 2008; Benninghoff et al., 2015; Krieg et al., 2017), which may increase the risk of ruminal acidosis (Plaizier et al., 2009). This, in combination with the lower energy content of rye grain as compared to maize grain (NRC, 2001), often leads to unwilling use of rye grain in diets for high-yielding dairy cows or finishing beef cattle (Micek, 2008). In contrast, when ruminants are fed grain containing starch that degrades slowly in the rumen, such as maize, substantial quantities of starch may avoid microbial fermentation in the rumen and become available for digestion in the small intestine (Tothi et al., 2003). Although post-ruminal starch digestion is energetically more favourable for ruminants (Sauvant, 1997), excessive starch escape from the rumen may limit microbial protein synthesis in the rumen, and thus the amount of protein available to the animal (Wang et al., 2009). Furthermore, because intestinal starch digestion in ruminants is limited (Owens et al., 1986), an excessive amount of starch entering the small intestine may cause starch to flow into the colon, leading to undesired starch fermentation in this part of the gastrointestinal tract (Mills et al., 1999).

Several strategies have been developed to accelerate or slow down the digestion kinetics of cereal grains in the rumen, depending on the intensity of grain fermentation in the rumen and the desired impact on livestock performance (Svihus et al., 2005). Physical processing of cereal grains for ruminants usually involves grinding (milling), cracking, flaking (rolling) or steam-flaking. Of these methods, cereal grains are commonly ground prior to feeding to increase nutrient availability as well as to facilitate mixing of grain with other feeds. Grinding breaks the pericarp, resulting in greater exposure of the endosperm to digestive enzymes. Therefore, the rate of starch digestion in the rumen increases inversely to the extent of kernel fragmentation (Ørskov, 1986). However, the final results of grain kernel processing can vary between cereal species or even cultivars. For example, the number of broken starch granules during grinding is influenced by the strength of the bond between the starch and the protein matrix surrounding the starch granules. In maize, the bond between the protein and starch is quite strong, resulting in a large number of broken starch granules in ground material (Hoseney, 1994) and a large surface area for digestion, which may at least partly explain why grinding increases ruminal degradation of starch more in maize than in rye, barley or wheat (Svihus et al., 2005; Micek, 2008).

The effects of cereal grain fragmentation and other grain processing methods on nutrient utilization by ruminants have been reviewed extensively (Ørskov, 1986; Rowe et al., 1999; Svihus et al., 2005). However, most studies have focused on the effect of physical treatment of grain on starch utilization, while much less attention has been devoted to crude protein (CP) utilization. When cereal grains account for a substantial proportion of dietary dry matter (DM), e.g. in diets for high-yielding cows or finishing beef cattle, a significant amount of protein is also supplied with cereal grains. Therefore, a full characterization of the nutritional value of cereal grains 
for ruminants requires knowledge not only of starch degradation in the rumen, but also protein degradation, as well as its post-ruminal digestion (Woods et al., 2003).

The hypothesis of this study was that although rye grain is more rapidly degraded in the rumen than maize grain, the site of its digestion along the gastrointestinal tract could be altered by grain fragmentation. The specific aim of the study was to characterize the ruminal degradability and post-ruminal digestibility of the DM, CP and starch of whole, crushed and coarsely or finely ground rye and maize grain using in sacco and in vitro methods.

\section{Material and methods}

The study was conducted at the Department of Animal Nutrition and Dietetics of the University of Agriculture in Krakow, Poland. Three fistulated cows were kept at the National Research Institute of Animal Production (Balice, Poland). Animal care procedures followed the recommendations of the Local Ethics Committee (Krakow, Poland).

\section{Materials}

Rye grain of a hybrid variety (Brasetto cultivar; KWS Lochow, Prusy, Poland) and maize grain (Podium cultivar; KWS Lochow, Prusy, Poland) were i) not processed (whole grain; WG), ii) crushed (with a ROmiLL S100 mill, BAG Polska, Krzemieniewo, Poland; CG); or ground (with a Pulverisette 15 Laboratory Cutting Mill, Fritsh GmbH, Idar-Oberstein, Germany) to pass through a iii) $4.0 \mathrm{~mm}$ sieve (coarsely ground; GG4.0) or iv) $1.5 \mathrm{~mm}$ sieve (finely ground; GG1.5). WG, CG, GG4.0 and GG1.5 were categorized as none, slight, moderate and extensive fragmentation of grain kernel. The aim of this study was to establish whether rye grain degradability in the rumen and post-ruminal digestion can be altered to any extent by processing intensity and method. Representative photos of processed cereal grains are presented in Figure 3.

\section{In sacco measurements}

Dry matter, CP and starch degradation in the rumen was determined in situ using the nylon bag technique as described by Ørskov and McDonald (1979) with minor modification (Kowalski et al., 1995). Three non-lactating Holstein-Friesian cows $(610 \pm 30 \mathrm{~kg})$ fitted with rumen cannulas and a T-shaped (gutter flange) duodenal cannulas were used for the study. The animals were fed $7.6 \mathrm{~kg}$ of DM/day of a diet consisting of $70 \%$ hay and $30 \%$ concentrate (DM basis). Feed was supplied in two equal meals at 8 a.m. and 4 p.m. The animals had free access to water and salt licks.

Four separated runs of the analysis for each cow were completed with 2 feeds incubated simultaneously within each run ( 4 runs $\times 2$ feeds). Additionally, each run was accompanied by 2 bags of standard feed (grass hay, $8 \mathrm{~h}$ of incubation) per cow with known DM. There were no differences between runs in DM degradability of standard feed and no corrections of in situ results were made. 
A

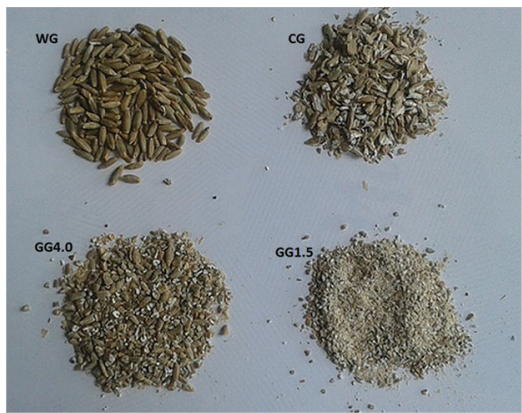

B

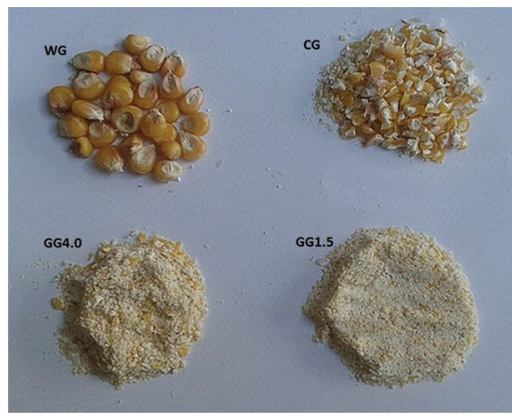

Figure 3. Rye grain of hybrid variety (A) and maize grain (B) processed to obtain four degrees of kernel fragmentation: whole grain (WG), crushed (CG), or ground to pass through a $4.0 \mathrm{~mm}$ sieve (coarsely ground; GG4.0) or a $1.5 \mathrm{~mm}$ sieve (finely ground; GG1.5)

Samples of $3.2 \mathrm{~g}$ of whole or processed grains were weighed into nylon bags (Ankom Technology, Fairport, NY, USA; pore size $50 \mu \mathrm{m}$; internal dimensions: $7 \times 12 \mathrm{~cm}$ ), yielding a ratio of sample mass per bag area of $19 \mathrm{mg} / \mathrm{cm}^{2}$. Bags were introduced in the rumen at the same time just before the morning feeding and pulled out after 2, 4, 8, 16, 24, 48 or $72 \mathrm{~h}$ of incubation. Twenty four measurements (eight replications for each of three cows) were made for each incubation time and each feed. After removal from the rumen, the bags were rinsed in cold water and frozen $\left(-20^{\circ} \mathrm{C}\right)$. After delivery to the laboratory, the bags were thawed and washed in a washing machine with two successive 10 min washings without centrifugation. Then they were dried at $60^{\circ} \mathrm{C}$ for $48 \mathrm{~h}$ and weighed. Residues from bags for each animal and for each incubation time separately were then pulled and used for performance of chemical analysis. Bags with samples of feed not incubated in the rumen (zero incubation time), handled similarly to the incubated ones, were used to estimate washing losses from bags. Prior to washing procedures, these bags were soaked in warm water $\left(39^{\circ} \mathrm{C}\right)$ for $30 \mathrm{~min}$.

Intestinal digestibility was determined as previously described by Peyraud et al. (1988) using polyester nitrogen-free bags (Ankom Technology; $6 \times 6 \mathrm{~cm}$, pore size $50 \mu \mathrm{m})$. Before incubation, the bags were rinsed with acetone and oven-dried for $1 \mathrm{~h}$ at $105^{\circ} \mathrm{C}$, and then filled with $1.2 \mathrm{~g}$ of sample, which was about $1.0 \mathrm{~g}$ of DM per bag. Four separate runs for each cow were completed with 2 samples (feeds) per run and twelve bags used per each sample ( 2 sample $\times 12$ bags). Additionally, 2 bags of standard feed (grass hay) per cow and per run were always analysed. Bags were pre-incubated in the rumen for $16 \mathrm{~h}$. Incubation began before afternoon feeding and was completed before morning feeding the next day. After removal from the rumen, the bags were pre-rinsed with tap water and then incubated at $39^{\circ} \mathrm{C}$ for $2.5 \mathrm{~h}$ in pepsin- $\mathrm{HCl}$ solution (Sigma-Aldrich, St. Louis, MO, USA; $3 \mathrm{~g}$ of pepsin per $1 \mathrm{~L}$ of $0.1 \mathrm{n} \mathrm{HCl}, \mathrm{pH}=2.0$ ). After incubation, the bags were rinsed with cold tap water and inserted into the duodenum (three bags simultaneously; 12 min intervals between sets of bags). Bags recovered from feces were pre-washed in tap water, then rinsed in a washing machine (two rinse cycles without centrifugation) and dried in an air- 
forced oven at $55^{\circ} \mathrm{C}$ for $48 \mathrm{~h}$, cooled in desiccators, and weighed. Residues from bags for each animal and for each sample were then pulled and used for performance of chemical analysis. Only bags recovered from feces within $24 \mathrm{~h}$ after insertion into the duodenum were used in this procedure.

\section{In vitro true digestibility}

In vitro true digestibility (IVTD) was carried out using F57 bags (Ankom Technology; $50 \times 55 \mathrm{~mm}$, pore size $25 \mu \mathrm{m}$ ) according to ANKOM Technology Method 3 (https://www.ankom.com/sites/default/files/document-files/Method_3_Invitro_D200_D200I.pdf). The bags were rinsed in acetone for $5 \mathrm{~min}$, dried $\left(2 \mathrm{~h}, 105^{\circ} \mathrm{C}\right)$ and weighed. Exactly $0.250 \mathrm{~g}$ of sample was weighed into the bag and then the bag was heat-sealed. At the same time, eight bags with each feed were incubated in four jars ( 2 bags per jar) and this procedure was repeated 3 times ( 3 runs). One bag per jar was left empty (blank sample) and one bag per jar was filled with a standard feed (grass hay with known IVTD). Pre-warmed buffer $\mathrm{A}\left(\mathrm{KH}_{2} \mathrm{PO}_{4}-10.0 \mathrm{~g} / \mathrm{L}, \mathrm{NaCl}-0.5\right.$ $\mathrm{g} / \mathrm{L}, \mathrm{MgSO}_{4} \times 7 \mathrm{H}_{2} \mathrm{O}-0.5 \mathrm{~g} / \mathrm{L}, \mathrm{CaCl}_{2} \times 2 \mathrm{H}_{2} \mathrm{O}-0.1 \mathrm{~g} / \mathrm{L}$, Urea $\left.-0.5 \mathrm{~g} / \mathrm{L} ; 39^{\circ} \mathrm{C}\right)$ and buffer $\mathrm{B}\left(\mathrm{Na}_{2} \mathrm{CO}_{3}-15.0 \mathrm{~g} / \mathrm{L}, \mathrm{Na}_{2} \mathrm{~S} \times 9 \mathrm{H}_{2} \mathrm{O}-1.0 \mathrm{~g} / \mathrm{L} ; 39^{\circ} \mathrm{C}\right)$ were mixed in a $5: 1 \mathrm{ra}-$ tio, and the $\mathrm{pH}$ was adjusted to 6.8 . A $160 \mathrm{~mL}$ volume of buffer solution was poured into each jar. Bags with samples were placed in the incubation jars 20 min before starting the incubation (this was the time necessary to prepare the inoculum).

Rumen digesta (both fluid and solid fractions) were collected before morning feeding from the three Holstein-Friesian cows previously used for the in sacco measurements. The digesta was blended (Standmixer, Bosch, type CNSM03ST) at the highest speed for $30 \mathrm{~s}$ and then filtered through four layers of cheesecloth into a preheated $\left(39^{\circ} \mathrm{C}\right)$ beaker. A $400 \mathrm{~mL}$ volume of filtered mixed digesta was added to each jar with buffer solution. The samples were incubated in a Daisy ${ }^{\mathrm{II}}$ Incubator (Ankom Technology) for $24 \mathrm{~h}$ at $39^{\circ} \mathrm{C}$. The inoculum was purged for $30 \mathrm{~s}$ with $\mathrm{CO}_{2}$ at each step of handling and preparation.

Bags removed from incubation jars were rinsed with cold tap water and placed in an ANKOM $^{200}$ Fiber Analyzer (Ankom Technology). The procedure described below for NDF determination was followed. After analysis, the bags were dried to constant weight in an air-forced oven at $55^{\circ} \mathrm{C}$, cooled in desiccators and weighed. IVTD was calculated as follows:

$$
\% I V T D=(D M \text { basis })=\frac{100-\left(W_{3}-\left[W_{1} \times C_{1}\right]\right)}{\left([W]_{2} \times D M\right)}
$$

where:

$W_{1}=$ bag tare weight $(\mathrm{g})$,

$W_{2}=$ sample weight $(\mathrm{g})$,

$W_{3}=$ final bag weight after in vitro incubation and sequential neutral detergent treatment $(\mathrm{g}), C_{1}=$ blank bag correction (final oven-dried weight/original blank bag weight). 


\section{Gas production technique}

In vitro gas production (GP) was determined using the ANKOM RF Gas Production System (Ankom Technology). The system consisted of 12 bottles equipped with pressure sensors (RF modules with a lid), a receiving base station, and a computer. For all experimental samples a total of 48 bottles ([ 4 treatments $\times 2$ cereal species +2 blanks +2 standard feed $=12)$ in 4 separate runs $(12 \times 4=48])$ were incubated. A standard feed was a grass hay with known GP24 and GP kinetics. Air-dried samples of feeds $(500 \mathrm{mg})$ were weighed in triplicate into $250 \mathrm{~mL}$ glass bottles and incubated overnight in a buffered solution (Goering and Van Soest, 1970) at $39^{\circ} \mathrm{C}$. Rumen digesta was collected as described for IVTD measurements. The digesta was filtered through two layers of cheesecloth and mixed with the buffer in a 1:5 ratio. A $125 \mathrm{~mL}$ volume of this mixture was poured into each bottle with a sample. Glass bottles were purged with $\mathrm{CO}_{2}$, closed with the lid, and incubated in a water bath with shaker for $24 \mathrm{~h}$ at $39^{\circ} \mathrm{C}$. Gas pressure in the bottles was recorded every $10 \mathrm{~min}$. Then the gas pressure change during $24 \mathrm{~h}$ of incubation $(\Delta \mathrm{P})$ was converted to gas volume (GP24, mL) using the ideal gas law (Tagliapietra et al., 2011):

$$
G P 24=(\Delta P / P o) \times V o
$$

where:

$\Delta P=$ cumulated pressure change (psi) in the bottle headspace,

$V o=$ bottle headspace volume $(\mathrm{ml})$,

$P o=$ atmospheric pressure measured by the equipment at the beginning of the study.

The final GP24 volume of bottles with no feed (blank) was subtracted from the final GP24 volume for bottles with feed to correct for baseline fermentation in the rumen fluid. In vitro organic matter digestibility (OMD) of samples was calculated from the volume of gas produced according to an equation proposed by Menke and Steingass (1988):

$$
O M D(\%)=14.88+0.889 G P 200+0.45 C P+0.065 A s h
$$

where:

$G P 200=$ cumulative gas production during 24 hour incubation expressed in $\mathrm{mL}$ per $200 \mathrm{mg}$ of DM,

$C P=$ crude protein content in the sample $(\% \mathrm{DM})$,

Ash $=$ crude ash in the sample $(\% \mathrm{DM})$.

\section{Chemical analysis}

Air-dried samples of rye and maize grain were ground to pass through a $1 \mathrm{~mm}$ sieve and analysed for content of DM, ash, CP and ether extract (EE) using standard analytical procedures (procedure nos. 934.01, 942.05, 976.05 and 920.39, for DM, ash, CP and EE, respectively; AOAC, 2005). Neutral detergent fibre, performed with heat-stable amylase (NDF; Mertens, 2002), acid detergent fibre (ADF; AOAC, 
2005; official method 973.18), and acid detergent lignin (ADL; Robertson and Van Soest, 1981) were determined using an Ankom ${ }^{220}$ Fiber Analyzer (Ankom Technology). The starch content was determined by an enzymatic method (Faisant et al., 1995). The same procedures were used for chemical analyses of the residues from the in sacco measurements and in vitro technique (IVTD). Total content of nonstarch polysaccharides (T-NSP), including water-soluble non-starch polysaccharides (WS-NSP) and water-insoluble non-starch polysaccharides (WIS-NSP), was determined by chromatography (Englyst and Cummings, 1984) as the sum of sugars: rhamnose, fructose, arabinose, xylose, mannose, galactose and glucose. Total dietary fibre (TDF; method no. 32-25; AACC, 2011) was determined as the sum of T-NSP, uronic acids, resistant starch and lignin.

\section{Calculations and statistical analysis}

Effective rumen degradability (ERD) and degradation constants (A, B, C) were calculated by the Marquardt method (NLIN procedure of SAS; SAS Inst. Inc., Cary, NC, USA) using an equation proposed by Ørskov and McDonald (1979):

$$
E R D(\%)=A+([B \times C] /[C+k])
$$

where:

$A=$ soluble fraction immediately degraded in the rumen $(\%)$,

$B=$ fraction degraded in the rumen at rate $\mathrm{C}(\%)$,

$C=$ rate of rumen degradability of fraction $\mathrm{B}(\% / \mathrm{h})$,

$k=$ rate of outflow from the rumen $0.06 / \mathrm{h}$.

Intestinal digestibility (ID) coefficients of by-pass DM, CP and starch were calculated according to Kowalski et al. (1995):

$$
I D(\%)=100 \times\left(F \times\left[100-R D_{10}\right]-F \times[100-T T D]\right) /\left(F \times\left[100-R D_{16}\right]\right)
$$

where:

$F=\mathrm{DM}$ or nutrient contents is sample before incubation $(\mathrm{g})$,

$R D_{16}=16 \mathrm{~h}$ rumen degradability $(\%)$,

$T T D=$ total tract digestibility $(\mathrm{TTD}(\%)=100 \times[\mathrm{F}-\mathrm{G}] / \mathrm{F})$,

$F=\mathrm{DM}$ or nutrient contents is sample recovered from feces $(\mathrm{g})$.

To calculate ID and total tract digestibility (TTD), $16 \mathrm{~h}$ ruminal degradability from the previously described in situ study was considered.

Data were subjected to two-way analysis of variance using PROC MIXED in SAS (SAS Inst. Inc., Cary, NC, USA). The statistical model included the effect of the cereal type (maize vs rye), grain fragmentation (WG, CG, GG4.0 or GG1.5), and the cereal type $\times$ grain fragmentation interaction, as fixed effects. When a significant effect of the interaction was found, means were separated using the PDIFF procedure in SAS with Duncan's adjustment. Data from in sacco studies (rumen degradability and intestinal digestibility parameters) were analysed by considering cow as the 
experimental unit. For in situ data, the calculations were performed for each animal, using the incubated bags at each time point as repeated measurements. IVTD data were analysed as a randomized complete block design, in which the incubation series (runs) was considered as a block and the mean value of the two bags of each sample in each experimental jar from each series as the experimental unit $(n=12)$. In the case of the results for 24 hour gas production (GP24) and organic matter digestibility (OMD), the model included individual bottles from each run as the experimental unit $(n=4)$. Linear regression between selected parameters was calculated using the REG procedure of SAS. Data are presented as least squares means and standard error of the mean (SEM). Differences between means were considered significant at $\mathrm{P}<0.05$.

\section{Results}

Compared with maize grain, rye grain had higher $\mathrm{CP}, \mathrm{NDF}, \mathrm{ADF}$ and ADL content, but lower starch and EE content (Table 1). T-NSP in rye grain was over two times higher than in maize grain, mainly due to WS-NSP content that was over five times higher in rye grain. Rye grain contained over twice as much TDF, arabinose, xylose and glucose, and over 10 times more galactose than maize grain.

Table 1. Chemical composition and carbohydrate structure of hybrid rye and maize grain ( $\mathrm{g} / \mathrm{kg} \mathrm{DM})$

\begin{tabular}{lrcc}
\hline \multicolumn{1}{c|}{ Item } & Rye grain & Maize grain \\
\hline Crude protein & 125.6 & 102.0 \\
Ether extract & 16.1 & 54.6 \\
Ash & 20.9 & 15.5 \\
Starch & 767.5 & 823.9 \\
NDF & 205.2 & 102.1 \\
ADF & 60.2 & 48.2 \\
ADL & 29.9 & 21.0 \\
NFC & & 725.8 \\
T-NSP & 2 & 632.2 & 67.3 \\
WIS-NSP $^{3}$ & 146.7 & 57.0 \\
WS-NSP $^{4}$ & 93.0 & 10.3 \\
TDF & 53.7 & 91.0 \\
Arabinose & 187.0 & 14.1 \\
Xylose & 33.0 & 16.6 \\
Mannose & 49.5 & 4.8 \\
Galactose & 6.2 & 0.4 \\
Glucose & 4.1 & 28.2 \\
\hline
\end{tabular}

${ }^{1}$ Non-fibre carbohydrates; NFC $=1000-(\mathrm{NDF}+\mathrm{CP}+\mathrm{EE}+\mathrm{Ash})$.

${ }^{2}$ Total content of non-starch polysaccharides.

${ }^{3}$ Water-insoluble non-starch polysaccharides.

${ }^{4}$ Water-soluble non-starch polysaccharides.

${ }^{5}$ Total dietary fibre. 
Irrespective of grain processing, ERD of DM was higher for rye grain than for maize grain (cereal grain, $\mathrm{P}<0.001$; Table 2). Fragmentation of rye grain increased the ERD of DM from $10.3 \%$ for $\mathrm{WG}$ to over $75 \%$ for processed grain. For processed rye, ERD of DM was lowest for GG4.0, intermediate for CG, and highest for GG1.5. For maize grain, ERD of DM increased with the degree of grain fragmentation, but did not exceed $55 \%$ (cereal grain $\times$ grain fragmentation interaction, $\mathrm{P}=0.001$ ). Furthermore, the difference between fragmentation methods was as high as $44 \%$ (CG vs GG1.5). In the case of processed rye grain, fraction A of DM was lowest for GG4.0, intermediate for $\mathrm{CG}$, and highest for GG1.5, while for processed maize grain, fraction A increased from CG to GG4.0 to GG1.5 (cereal grain $\times$ grain fragmentation interaction, $\mathrm{P}=0.001$ ).

The ID and TTD of DM for processed rye grain were close to or exceeded $90 \%$ (Table 2). On the other hand, the ID and TTD of DM for processed maize grain increased from CG to GG1.5, with values comparable to those observed for rye grain only for GG1.5 maize (cereal grain $\times$ grain fragmentation interaction, $\mathrm{P} \leq 0.026$ ). Furthermore, TTD of DM for WG rye was much higher than for WG maize (53.2 vs $17.7 \%$ for rye and maize grain, respectively).

Table 2. Effect of grain fragmentation on effective rumen degradability (ERD), degradability constants (A, B, C), intestinal digestibility (ID) and total tract digestibility (TTD) of dry matter of hybrid rye and maize grain

\begin{tabular}{|c|c|c|c|c|c|c|c|}
\hline Item & $\begin{array}{c}\text { Grain } \\
\text { fragmentation }^{1}\end{array}$ & A (\%) & B (\%) & $\mathrm{C}(\% / \mathrm{h})$ & ERD (\%) & ID (\%) & TTD (\%) \\
\hline \multirow[t]{4}{*}{ Cereal grain Rye } & WG & $1.6 \mathrm{e}$ & $96.7 \mathrm{a}$ & $1.2 \mathrm{c}$ & $10.3 \mathrm{~g}$ & $45.3 \mathrm{e}$ & $53.2 \mathrm{~d}$ \\
\hline & CG & $52.3 \mathrm{~b}$ & $41.7 \mathrm{ef}$ & $11.3 \mathrm{~b}$ & $79.8 \mathrm{~b}$ & $92.3 \mathrm{a}$ & $93.5 \mathrm{a}$ \\
\hline & GG4.0 & $27.6 \mathrm{c}$ & $63.5 \mathrm{~cd}$ & $19.0 \mathrm{a}$ & $75.8 \mathrm{a}$ & $89.3 \mathrm{~b}$ & $90.9 \mathrm{~b}$ \\
\hline & GG1.5 & $65.7 \mathrm{a}$ & $28.3 \mathrm{f}$ & $18.3 \mathrm{a}$ & $86.8 \mathrm{c}$ & $91.9 \mathrm{a}$ & $93.2 \mathrm{a}$ \\
\hline \multirow[t]{4}{*}{ Maize } & WG & $1.1 \mathrm{e}$ & $50.6 \mathrm{de}$ & $0.5 \mathrm{c}$ & $4.4 \mathrm{~h}$ & $13.6 \mathrm{f}$ & $17.7 \mathrm{e}$ \\
\hline & CG & $2.2 \mathrm{e}$ & $97.1 \mathrm{a}$ & $2.2 \mathrm{c}$ & $30.9 \mathrm{f}$ & $52.6 \mathrm{~d}$ & $54.8 \mathrm{~d}$ \\
\hline & GG4.0 & $11.2 \mathrm{~d}$ & $88.2 \mathrm{ab}$ & $4.3 \mathrm{c}$ & $47.3 \mathrm{e}$ & $74.3 \mathrm{c}$ & $75.5 \mathrm{c}$ \\
\hline & GG1.5 & $29.9 \mathrm{c}$ & $76.3 \mathrm{bc}$ & $4.1 \mathrm{c}$ & $54.8 \mathrm{~d}$ & $93.0 \mathrm{a}$ & $93.3 \mathrm{a}$ \\
\hline \multirow[t]{3}{*}{ Effect (P-value) } & Grain $(\mathrm{G})$ & $<0.001$ & $<0.001$ & $<0.001$ & $<0.001$ & 0.001 & 0.001 \\
\hline & Fragmentation $(\mathrm{F})$ & $<0.001$ & $<0.001$ & 0.036 & $<0.001$ & $<0.001$ & $<0.001$ \\
\hline & $\mathrm{G} \times \mathrm{F}^{2}$ & 0.001 & $<0.001$ & 0.002 & 0.001 & 0.026 & 0.003 \\
\hline SEM & & 1.76 & 3.47 & 0.98 & 0.56 & 2.46 & 2.31 \\
\hline
\end{tabular}

${ }^{\mathrm{a}, \mathrm{b}, \mathrm{c}}$ Means within a column with different superscripts are significantly different $(\mathrm{P} \leq 0.01)$.

${ }^{1} \mathrm{WG}$ - whole grain; CG - crushed grain; GG4.0 - grain ground to pass through $4.0 \mathrm{~mm}$ sieve; GG1.5 - grain ground to pass through $1.5 \mathrm{~mm}$ sieve.

${ }^{2}$ Interaction between cereal grain and grain fragmentation.

As in the case of ERD of DM, ERD of starch was much higher for rye grain than for maize grain (cereal grain, $\mathrm{P}<0.001$; Table 3 ), and grain fragmentation increased 
the ERD of rye starch from $18.3 \%$ for WG to over $85 \%$ for processed grain. Starch of processed rye grain, especially CG and GG1.5, was rapidly degraded during the first $8 \mathrm{~h}$ of incubation in the rumen (Figure $1 \mathrm{~A}$ ). On the other hand, the ERD of maize grain starch increased with the degree of grain fragmentation, but did not exceed $57.5 \%$ (cereal grain $\times$ grain fragmentation interaction, $\mathrm{P}=0.001$ ). Furthermore, as in the case of ERD of DM, ERD of starch for processed rye grain was lowest for GG4.0, intermediate for CG, and highest for GG1.5, but the difference between processed grains did not exceed $11 \%$, as compared with $36 \%$ differences between differently processed maize grains. For processed rye, fraction A of starch was lowest for GG4.0, intermediate for CG, and highest for GG1.5, whereas for maize grain, fraction A increased from CG to GG4.0 to GG1.5 (cereal grain $\times$ grain fragmentation interaction, $\mathrm{P}=0.001$ ). The reverse results were observed for fraction $\mathrm{B}$. Effective rumen degradability of starch for WG was very low.

Starch of processed rye grain was nearly completely digested in the total digestive tract $(>99 \%)$, whereas such high digestion of starch for maize grain was observed only for GG1.5 maize (cereal grain $\times$ grain fragmentation interaction, $\mathrm{P}=0.006$; Table 3 ). On the other hand, ID of starch for rye grain increased with grain fragmentation, whereas for maize grain it was lowest for GG4.0, intermediate for CG, and highest for GG1.5; however, the difference between CG and GG4.0 was only 2\%. It is worth noting that both ID and TTD of starch for WG rye exceeded $50 \%$, whereas ID and TTD of starch for WG maize was under $25 \%$.

Table 3. Effect of processing on degradability constants (A, B, C), effective rumen degradability (ERD), intestinal digestibility (ID) and total tract digestibility (TTD) of starch of hybrid rye and maize grain

\begin{tabular}{|c|c|c|c|c|c|c|c|}
\hline Item & $\begin{array}{c}\text { Grain } \\
\text { fragmentation }^{1}\end{array}$ & $\mathrm{~A}(\%)$ & B $(\%)$ & $\mathrm{C}(\% / \mathrm{h})$ & ERD $(\%)$ & ID (\%) & TTD (\%) \\
\hline \multirow[t]{4}{*}{ Cereal grain Rye } & WG & 8.8 ef & $86.9 \mathrm{ab}$ & $2.4 \mathrm{~d}$ & $18.3 \mathrm{~g}$ & $56.4 \mathrm{~d}$ & $64.9 \mathrm{c}$ \\
\hline & CG & $49.3 \mathrm{~b}$ & $49.4 \mathrm{~d}$ & $50.5 \mathrm{a}$ & $92.5 \mathrm{~b}$ & $73.0 \mathrm{bc}$ & $99.2 \mathrm{a}$ \\
\hline & GG4.0 & $37.7 \mathrm{c}$ & $60.3 \mathrm{c}$ & $25.3 \mathrm{bc}$ & $85.5 \mathrm{c}$ & $87.2 \mathrm{~b}$ & $99.1 \mathrm{a}$ \\
\hline & GG1.5 & $71.6 \mathrm{a}$ & $27.9 \mathrm{e}$ & $48.2 \mathrm{ab}$ & $96.0 \mathrm{a}$ & $100.0 \mathrm{a}$ & $100.0 \mathrm{a}$ \\
\hline \multirow[t]{4}{*}{ Maize } & WG & $1.2 \mathrm{f}$ & $36.5 \mathrm{e}$ & $0.1 \mathrm{~d}$ & $4.6 \mathrm{~h}$ & $19.9 \mathrm{e}$ & $24.9 \mathrm{e}$ \\
\hline & CG & $3.5 \mathrm{f}$ & $96.0 \mathrm{a}$ & $2.3 \mathrm{~d}$ & $36.9 \mathrm{f}$ & $58.7 \mathrm{c}$ & $61.3 \mathrm{~d}$ \\
\hline & GG4.0 & $12.2 \mathrm{e}$ & $87.3 \mathrm{ab}$ & $4.2 \mathrm{~cd}$ & $50.5 \mathrm{e}$ & $55.3 \mathrm{~d}$ & $81.9 \mathrm{~b}$ \\
\hline & GG1.5 & $21.4 \mathrm{~d}$ & $78.3 \mathrm{~b}$ & $4.0 \mathrm{~cd}$ & $57.5 \mathrm{~d}$ & $98.0 \mathrm{a}$ & $99.2 \mathrm{a}$ \\
\hline \multirow[t]{3}{*}{ Effect (P-value) } & Grain (G) & $<0.001$ & $<0.001$ & 0.001 & $<0.001$ & $<0.001$ & $<0.001$ \\
\hline & Fragmentation $(\mathrm{F})$ & $<0.001$ & $<0.001$ & $<0.001$ & $<0.001$ & $<0.001$ & $<0.001$ \\
\hline & $\mathrm{G} \times \mathrm{F}^{2}$ & 0.001 & 0.001 & 0.003 & 0.001 & 0.002 & 0.006 \\
\hline SEM & & 1.66 & 1.87 & 1.09 & 0.21 & 2.61 & 2.26 \\
\hline
\end{tabular}

${ }^{a, b, c}$ Means within a column with different superscripts are significantly different $(\mathrm{P} \leq 0.01)$.

${ }^{1} \mathrm{WG}$ - whole grain; $\mathrm{CG}$ - crushed grain; GG4.0 - grain ground to pass through $4.0 \mathrm{~mm}$ sieve; GG1.5 - grain ground to pass through $1.5 \mathrm{~mm}$ sieve.

${ }^{2}$ Interaction between cereal grain and grain fragmentation. 
Irrespective of grain processing, ERD of $\mathrm{CP}$ was about two times higher for rye grain than for maize grain (cereal grain, $\mathrm{P}=0.001$; Table 4). Fragmentation of rye grain increased the ERD of CP from $15.9 \%$ for $\mathrm{WG}$ to $83.8 \%$ for processed grain. Most of the CP of processed rye grain was degraded in the first $8 \mathrm{~h}$ of incubation in the rumen (Figure $1 \mathrm{~B}$ ). For processed rye, ERD of CP was lowest for GG4.0, intermediate for CG, and highest for GG1.5. ERD of CP for maize grain increased with the degree of grain fragmentation (cereal grain $\times$ grain fragmentation interaction, $\mathrm{P}<0.001$ ), and difference between fragmentation methods was as high as $51 \%$ (CG vs GG1.5). In the case of processed rye grain, fraction A of CP was lowest for GG4.0, intermediate for CG, and highest for GG1.5, whereas for processed maize grain, fraction A increased from CG to GG4.0 to GG1.5 (cereal grain $\times$ grain fragmentation interaction, $\mathrm{P}<0.001$ ). Effective rumen degradability of $\mathrm{CP}$ for whole grain was $15.9 \%$ and $6.9 \%$ for rye and maize grain, respectively.

Table 4. Effect of processing on effective rumen degradability (ERD), degradability constants (A, B, C), intestinal digestibility (ID) and total tract digestibility (TTD) of crude protein of hybrid rye and maize grain

\begin{tabular}{|c|c|c|c|c|c|c|c|}
\hline Item & $\begin{array}{c}\text { Grain } \\
\text { fragmentation }^{1}\end{array}$ & $\mathrm{~A}(\%)$ & B (\%) & $\mathrm{C}(\% / \mathrm{h})$ & ERD (\%) & ID (\%) & TTD (\%) \\
\hline \multirow[t]{8}{*}{ Cereal grain } & WG & $6.0 \mathrm{e}$ & $90.8 \mathrm{ab}$ & $1.0 \mathrm{c}$ & $15.9 \mathrm{~g}$ & $49.6 \mathrm{e}$ & $53.9 \mathrm{e}$ \\
\hline & CG & $31.7 \mathrm{~b}$ & $61.0 \mathrm{~d}$ & $2.2 \mathrm{a}$ & $78.6 \mathrm{~b}$ & $66.4 \mathrm{~b}$ & $95.1 \mathrm{a}$ \\
\hline & GG4.0 & $27.4 \mathrm{bc}$ & $65.9 \mathrm{~cd}$ & $13.1 \mathrm{~b}$ & $74.0 \mathrm{c}$ & $64.7 \mathrm{c}$ & $93.9 \mathrm{~b}$ \\
\hline & GG1.5 & $55.0 \mathrm{a}$ & $41.0 \mathrm{e}$ & $14.4 \mathrm{~b}$ & $83.8 \mathrm{a}$ & $62.1 \mathrm{c}$ & $95.7 \mathrm{a}$ \\
\hline & WG & $2.4 \mathrm{e}$ & $43.6 \mathrm{e}$ & $0.2 \mathrm{c}$ & $6.9 \mathrm{~h}$ & $2.0 \mathrm{f}$ & $9.7 \mathrm{f}$ \\
\hline & $\mathrm{CG}$ & $2.2 \mathrm{e}$ & $97.2 \mathrm{a}$ & $1.3 \mathrm{c}$ & $25.4 \mathrm{f}$ & $56.8 \mathrm{~d}$ & $60.2 \mathrm{~d}$ \\
\hline & GG4.0 & $16.3 \mathrm{~d}$ & $80.6 \mathrm{abc}$ & $3.0 \mathrm{c}$ & $43.5 \mathrm{e}$ & $57.4 \mathrm{~d}$ & $78.6 \mathrm{c}$ \\
\hline & GG1.5 & $21.4 \mathrm{~cd}$ & $78.1 \mathrm{bcd}$ & $3.1 \mathrm{c}$ & $51.6 \mathrm{~d}$ & $91.3 \mathrm{a}$ & $95.9 \mathrm{a}$ \\
\hline \multirow[t]{3}{*}{ Effect (P-value) } & Grain (G) & 0.001 & 0.007 & $<0.001$ & $<0.001$ & $<0.001$ & 0.001 \\
\hline & Fragmentation $(\mathrm{F})$ & $<0.001$ & 0.003 & $<0.001$ & $<0.001$ & $<0.001$ & $<0.001$ \\
\hline & $\mathrm{G} \times \mathrm{F}^{2}$ & $<0.001$ & 0.001 & 0.001 & $<0.001$ & 0.009 & 0.007 \\
\hline SEM & & 1.68 & 3.50 & 0.69 & 0.42 & 2.43 & 2.54 \\
\hline
\end{tabular}

${ }^{\mathrm{a}, \mathrm{b}, \mathrm{c}}$ Means within a column with different superscripts are significantly different $(\mathrm{P} \leq 0.01)$.

${ }^{1} \mathrm{WG}$ - whole grain; CG - crushed grain; GG4.0 - grain ground to pass through $4.0 \mathrm{~mm}$ sieve; GG1.5 - grain ground to pass through $1.5 \mathrm{~mm}$ sieve.

${ }^{2}$ Interaction between cereal grain and grain fragmentation.

Irrespective of grain processing, ID of CP for rye grain did not exceed $67 \%$, whereas it increased to $91.3 \%$ for GG1.5 maize (cereal grain $\times$ grain fragmentation interaction, $\mathrm{P}=0.009$; Table 4). TTD of $\mathrm{CP}$ for processed rye grain was close to or higher than $95 \%$, whereas such a high TTD of CP was found only for GG1.5 maize (cereal grain $\times$ grain fragmentation interaction, $\mathrm{P}=0.007$ ).

Irrespective of grain type, GP24 was the lowest and even negative for WG (Table 5, Figure 2). On the other hand, GP24 was higher for CG rye compared with CG maize as well as higher for GG1.5 rye compared with GG1.5 maize, indicating higher GP24 for processed rye grain (cereal grain $\times$ grain fragmentation interaction, 
$\mathrm{P}<0.001$ ). Since OMD was calculated based on GP24, similar differences between treatments were observed for this parameter. Irrespective of grain fragmentation, rye grain had higher OMD than maize grain. A significant cereal grain $\times$ grain fragmentation interaction $(\mathrm{P}=0.001)$ confirmed different effects of grain fragmentation on OMD within each cereal.

A



B

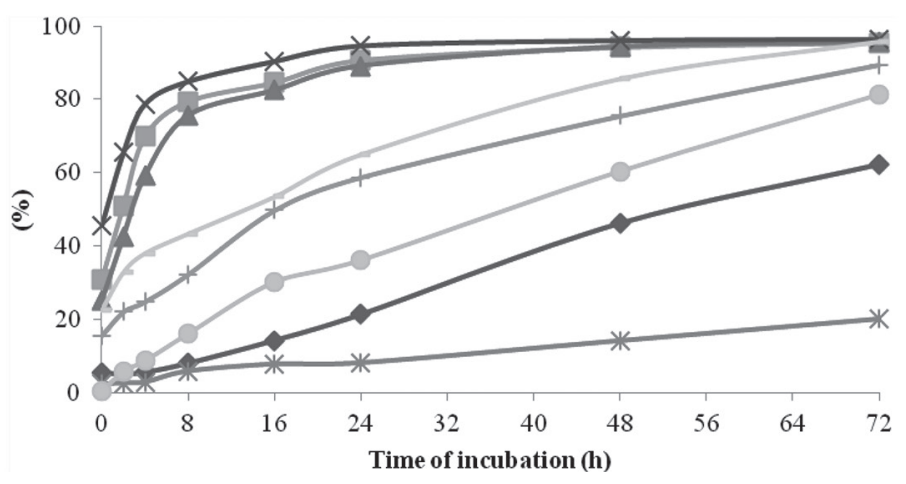

WG - whole grain; CG - crushed grain; GG4.0 - ground grain to pass through $4.0 \mathrm{~mm}$ sieve; GG1.5 ground grain to pass through $1.5 \mathrm{~mm}$ sieve.

Figure 1. In situ starch (A) and CP (B) degradability in the rumen of hybrid rye and maize depending on grain processing

Irrespective of grain type, IVTD considerably increased from WG to GG1.5 (grain fragmentation, $\mathrm{P}<0.001$; Table 5). However, IVTD for $\mathrm{WG}$ rye was higher than for WG maize (23.0\% vs 2.6\%, respectively), whereas GG4.0 and GG1.5 maize had higher IVTD than rye grain processed in the same way. Furthermore, IVTD for CG rye was higher than for GG4.0 rye (cereal grain $\times$ grain fragmentation interaction, $\mathrm{P}<0.001)$. 




WG - whole grain; CG - crushed grain; GG4.0 - ground grain to pass through $4.0 \mathrm{~mm}$ sieve; GG1.5 ground grain to pass through $1.5 \mathrm{~mm}$ sieve.

Figure 2. Cumulative gas production of hybrid rye and maize depending on grain processing

Table 5. In vitro gas production (GP24), organic matter digestibility (OMD) estimated by the gas production technique during 24 hour incubation, and in vitro true digestibility (IVTD) of hybrid rye and maize grain

\begin{tabular}{cll|c|c|c}
\hline \multicolumn{2}{c|}{ Item } & \multicolumn{1}{c|}{$\begin{array}{c}\text { Grain } \\
\text { fragmentation }\end{array}$} & GP24 (ml) & OMD (\%) & IVTD (\%) \\
\hline Cereal grain & Rye & WG & $-1.42 \mathrm{e}$ & $18.8 \mathrm{e}$ & $23.0 \mathrm{~d}$ \\
& & CG & $35.97 \mathrm{c}$ & $52.0 \mathrm{c}$ & $90.7 \mathrm{~b}$ \\
& GG4.0 & $32.67 \mathrm{c}$ & $49.1 \mathrm{c}$ & $88.9 \mathrm{~b}$ \\
& GG1.5 & $44.14 \mathrm{a}$ & $59.3 \mathrm{a}$ & $91.7 \mathrm{a}$ \\
& Maize & WG & $-2.83 \mathrm{e}$ & $16.7 \mathrm{e}$ & $2.6 \mathrm{e}$ \\
& CG & $19.79 \mathrm{~d}$ & $36.8 \mathrm{~d}$ & $83.0 \mathrm{c}$ \\
& GG4.0 & $32.98 \mathrm{c}$ & $48.6 \mathrm{c}$ & $93.6 \mathrm{a}$ \\
& GG1.5 & $40.68 \mathrm{~b}$ & $55.4 \mathrm{~b}$ & $93.4 \mathrm{a}$ \\
Effect (p-value) & Grain (G) & $<0.001$ & $<0.001$ & $<0.001$ \\
& Fragmentation (F) & $<0.001$ & $<0.001$ & $<0.001$ \\
& G $\times \mathrm{F}^{2}$ & $<0.001$ & 0.001 & $<0.001$ \\
SEM & & 3.59 & 3.20 & 4.29 \\
\hline
\end{tabular}

${ }^{\mathrm{a}, \mathrm{b}, \mathrm{c}} \mathrm{M}$ Means within a column with different superscripts are significantly different $(\mathrm{P} \leq 0.01)$.

${ }^{1} \mathrm{WG}$ - whole grain; CG - crushed grain; GG4.0 - grain ground to pass through $4.0 \mathrm{~mm}$ sieve; GG1.5 - grain ground to pass through $1.5 \mathrm{~mm}$ sieve.

${ }^{2}$ Interaction between cereal grain and grain fragmentation.

\section{Discussion}

The main aim of mechanical processing of cereal grains for ruminants is to break the pericarp on the outside of the kernel in order to increase microbial access to starch and thereby enhance ruminal starch digestibility. However, depending on the 
physical properties of cereal grain (e.g. pericarp thickness) and fermentation characteristics of starch, optimal fragmentation of the kernel may differ depending on the cereal grain. Furthermore, significant differences in the rate and extent of starch degradation in the rumen have been observed between different varieties of the same crop plant (Philippeau and Michalet-Doreau, 1998; Micek, 2008). Given that each year new varieties of crop plants are available on the market (e.g. hybrid varieties of rye), there is a continuous demand for digestibility trials evaluating the nutritive value of these 'new' feeds.

In the present study, processed hybrid rye grain was generally rapidly degraded in the rumen, and this degradability was only marginally affected by the method of kernel fragmentation. Rapid degradation of rye grain in the rumen, in particular rye starch, has been shown in other studies (Micek, 2008; Krieg et al., 2017). On the other hand, maize starch is degraded in the rumen to a lesser extent, resulting in a greater amount of starch bypassing the rumen (Philippeau et al., 1999; Rémond et al., 2004; Svihus et al., 2005). According to McAllister et al. (1993), the protein matrix and structural carbohydrates present in the kernel largely determine ruminal starch digestibility. For example, the content of some proteins (e.g. albumins, globulins, and prolamins) and their distribution in the endosperm differ between different cereal grains (Nikokyris and Kandylis, 1997). This in turn affects the susceptibility of protein to microbial fermentation (Seifried et al., 2016), resulting in differences in the ruminal digestibility of starch (Svihus et al., 2005; Krieg et al., 2017). Furthermore, based on the results of an in vitro study, Crowe et al. (2000) argue that the interaction between amylose and fatty acids present within the kernel may be an important factor, reducing the rate of enzymatic digestion of starch. Fat content is higher in maize grain than in rye grain (in the present study $54.6 \mathrm{vs} 16.1 \mathrm{~g} / \mathrm{kg}$ DM for maize and rye grain, respectively). This may explain the greater impact of the physical processing of maize grain on its ruminal digestion, due to the more intensive processing needed to destroy chemical bonds between nutrients and ensure that ruminal microbes have access to these nutrients. It is also worth noting that T-NSP and soluble sugars found in rye grain, such as glucose, fructose, sucrose or fructans, may contribute to the high ruminal fermentability of rye grain. Rye contains significant levels of phenolic compounds and water-soluble polysaccharides, especially arabinoxylans. Moreover, the content of fructans in rye grain is four to ten times higher than in wheat grain (Andersson et al., 2014). The presence of these carbohydrates in rye grain and their impact on the ruminal digestibility of rye grain requires detailed studies.

As mentioned above, processing is necessary to break the pericarp of the kernel in order to improve grain digestibility. However, rapid ruminal fermentation of starch may lead to digestive upsets in ruminants (Plaizier et al., 2009). Substantial reduction of kernel particle size due to grinding increases the rate and extent of grain fermentation in the rumen (Bertipaglia et al., 2010), which is not necessarily desired when cereal grains that are highly fermentable in the rumen are used as feed. Therefore, crushing of cereal grain may be a better method of fragmentation of rye kernels. In the present study, however, ERD of DM and starch for CG rye was even higher than for GG4.0 rye, confirming that the intensive ruminal fermentation of rye starch is independent of the intensity of kernel processing. The higher ERD of DM 
and starch for CG rye than GG4.0 rye is difficult to explain, but could simply be due to more effective breaking of the pericarp of rye grain by crushing than by passing through a $4.0 \mathrm{~mm}$ sieve. Given the diameter of rye grain $(\approx 3-4 \mathrm{~mm})$, some kernels could pass through a $4.0 \mathrm{~mm}$ sieve intact (Figure 3 ). However, based on the results of the present study, moderate fragmentation of rye grain (e.g. by passing through a $4.0 \mathrm{~mm}$ sieve) could be recommended for practical use. Compared to crushing, this mechanical processing method may at least partially reduce the rate and extent of rye grain digestibility in the rumen, without compromising intestinal digestibility. As the TTD of maize grain starch was highest when grain was ground to pass through a $4.0 \mathrm{~mm}$ sieve, moderate fragmentation of maize grain can be also recommended.

In line with the results of the present study, Philippeau et al. (1999) showed that ruminal degradation of starch was lower for crushed than for ground maize grain. Furthermore, similarly to the results of the present study, higher ERD was accompanied by higher content of fraction A and a higher starch degradation rate (constant C). Also, Knowlton et al. (1998) demonstrated that ground maize grain had a higher rate of in vitro starch digestion than crushed grain. On the other hand, when different methods of processing were applied to maize grain, a decrease in ruminal starch digestibility was associated with a decrease in small intestinal starch digestibility in cattle (Rémond et al., 2004). In general, our study showed that post-ruminal digestion of maize starch increased with the processing intensity of the grain, as opposed to the negligible effect of processing intensity on the post-ruminal digestibility of rye grain. Since enzymatic digestion of starch escaping the rumen and entering the small intestine is energetically more efficient for ruminants than utilization of ruminal short-chain fatty acids (Offner and Sauvant, 2004), the site of starch digestion along the gastrointestinal tract may have a substantial effect on dairy or beef cattle performance. As a result, the effect of maize grain processing on postruminal digestion should be taken into account when formulating diets for ruminants, whereas such an impact on post-ruminal rye grain digestibility is much less evident.

It is worth noting that rapid degradation of rye grain in the rumen is also a result of its rapid CP degradation. According to McAllister et al. (1993) and Krieg et al. (2017), interactions of the protein matrix with starch granules and variation in the properties of cereal grain proteins could contribute to differences in starch degradation kinetics. In the present study, the kinetics of in situ CP degradation did in fact show a similar trend to that observed for the kinetics of starch degradation. Furthermore, the correlation between ERD of starch and ERD of CP was high $(r=0.995)$, supporting the widely suggested (Svihus et al., 2005; Krieg et al., 2017) impact of solubility and susceptibility of protein to ruminal fermentation on ERD of starch.

The in situ nylon bag technique is commonly used to characterize the degradation and kinetics of degradation of feeds (their components) in the rumen. However, in this technique, small particles of grain (starch granules) may escape from the bag without being degraded by ruminal microbes. The data provided by Offner and Sauvant (2004) suggest that the in situ technique underestimates ruminal starch degradability for slowly degradable starch sources, such as maize, and overestimates it for rapidly degradable starch sources such as rye. Therefore, ideally several methods should be applied to fully characterize the nutritive value of cereal grains for rumi- 
nants. In the present study, a high correlation was observed between in situ ERD of $\mathrm{DM}$ and in vitro GP24 or OMD ( $r=0.92$ and $r=0.93$, respectively), suggesting that in vitro techniques could be used to provide a simulation of the in situ situation with almost equal effectiveness. In general, the results obtained by the in situ and in vitro GP technique were comparable, with both confirming very rapid rumen degradation of DM and starch for rye grain, while the method of kernel fragmentation had only a minor impact on this process. However, a negative gas production value after $8 \mathrm{~h}$ of incubation was shown for WG. A similar 'problem' has been reported by Araujo et al. (2011). According to our best hypothesis, the easily degradable fraction of organic matter contained in jars with WG was probably entirely used up by the microbial population during the first $8 \mathrm{~h}$ of incubation. Then, in the next $16 \mathrm{~h}$, the amount of gas produced gradually decreased, even below the values observed for blanks. This means that after $14 \mathrm{~h}$ of incubation, the gas production in samples containing $\mathrm{WG}$ of rye or corn were lower than in blank samples containing only buffered rumen fluid. This biologically inappropriate effect is not clear and difficult to explain but we hypothesize that the reduction in gas production in WG jars may suggest that the addition of untreated grains significantly affects fermentation of organic matter, not only derived from substrate, but also from the inoculum.

Compared to the in situ and GP method, the IVTD technique is an easier and less time-consuming method of predicting DM digestibility in the rumen. However, IVTD seems to be the less useful method for differentiating the impact of grain processing on its digestibility in the rumen. Its use is limited to feeds that do not contain a high level of small indigestible derivatives that might escape from the bag during incubation (Mabjeesh et al., 2000). Grains become floury when ground. Therefore, sample processing, particularly grinding intensity, interacts with the pore size of the bag and affects the extent of feed disappearance. As a result, the differences between processed grains can largely be explained by differences in the final particle size of the sample, which is also the case for the in situ method. However, the latter method measures the disappearance of feed nutrients in time, which in turn affects degradability. Thus, the time criterion is more relevant for the in situ method, where so-called washing losses from bags are considered a ' 0 ' incubation time and the inclusion of different incubation times allows for measuring the rate of digestion. The $24 \mathrm{~h}$ incubation time used in the present study for IVTD seems to be sufficient for comparing the digestion of cereal grains, but the final results are still associated with error due to the potential escape of undigested material from the bag. On the other hand, the use of a $48 \mathrm{~h}$ incubation time instead of $24 \mathrm{~h}$ would probably result in complete digestion of samples of processed grains.

In conclusion, the greater degree of rye and maize grain fragmentation, the higher effective rumen degradability and intestinal digestibility of starch. However, rye starch and crude protein are more susceptible to fermentation in the rumen than maize, and way of grain processing may alter the site and extent of its digestion along the gastrointestinal tract. In this context, grain fragmentation may affect rumen degradability and post-ruminal digestion to a much greater extent for maize grain than rye grain. 


\section{Acknowledgements}

The authors acknowledge the staff of the National Research Institute of Animal Production (Balice, Poland) for their help in conducting the study on fistulated cows and collecting the data.

\section{References}

AACC (2011). International approved methods of analysis. 11th ed. St. Paul, MN, USA.

A n d e r s s o n A.A.M., D i m b e r g L., Å m a n P., L a n d b e r g R. (2014). Recent findings on certain bioactive components in whole grain wheat and rye. J. Cereal Sci., 59: 294-311.

AOAC (2005). Association of Official Analytical Chemists. Official methods of analysis. 18th ed. AOAC International, Washington, DC.

A ra ujo R.C., P ires a A.V., M ou rã o a G.B., A b d a 11 a b A.L., S a 11 a m c S.M.A. (2011). Use of blanks to determine in vitro net gas and methane production when using rumen fermentation modifiers. Anim. Feed Sci. Tech., 166-167: 155-162.

B e nn inghoff J., P a s chke-B e e se M., Süd e kum K.H. (2015). In situ and in vitro ruminal degradation of maize grain and untreated or xylose-treated wheat, barley and rye grains. Anim. Feed Sci. Tech., 210: 86-93.

B ertip a gli a L.M.A., F onde vila M., van L a a r H., Cas trillo C. (2010). Effect of pelleting and pellet size of a concentrate for intensively reared beef cattle on in vitro fermentation by two different approaches. Anim. Feed Sci. Tech., 159: 88-95.

Crowe T.C., S e lig m an S.A., C o pel and L. (2000). Inhibition of enzymic digestion of amylose by free fatty acids in vitro contributes to resistant starch formation. J. Nutr., 130: 2006-2008.

E n g l y s t H.N., C u m m in g s J.H. (1984). Simplified method for the measurement of total non-starch polysaccharides by gas-liquid chromatography of constituent sugars as alditol acetates. Analyst, 109: 937-942.

Fais ant N., Planchot V., Kozlowski F., Pacourent M.P., Colonna P., Champ M. (1995). Resistant starch of determination adapted to products containing high level of resistant starch. Sci. Alim., 15: 83-89.

G o e r in g H.K., Van S o e st P.J. (1970). Forage fibre analysis. In: Agricultural Handbook No. 379. Agricultural Research service, USDA, Washington, DC, $20 \mathrm{pp}$.

Grajewski J., Błajet-Kosicka A., Twarużek M., Kosicki R. (2012). Occurrence of mycotoxins in Polish animal feed in years 2006-2009. J. Anim. Physiol. Anim. Nutr., 95: 870-877.

H o s e n e y R.C. (1994). Principles of cereal science and technology. American Association of Cereal Chemists, St. Paul, USA.

Kn ow lt on K.F., Glen n B.P., Erdman R.A. (1998). Performance, ruminal fermentation, and site of starch digestion in early lactation cows fed corn grain harvested and processed differently. J. Dairy Sci., 81: 1972-1984.

K ow a 1 s k i Z.M., P i s u 1 e w s k i P.M.P., P e y r a u d J-L., K a m iń s k i J. (1995). The effect of drier outflow temperature on rumen protein degradability and intestinal digestibility of rumen-undegraded protein of dehydrated grass and lucerne. Ann. Zootech., 44 (suppl.1): 88.

K ri eg J., S e ifried N., S te ingas s H., R od ehutscord M. (2017). In situ and in vitro ruminal starch degradation of grains from different rye, triticale and barley genotypes. Animal, 11: $1745-1753$.

Mabjeesh S.J., Cohen M., Arieli A. (2000). In vitro methods for measuring the dry matter digestibility of ruminant feedstuffs: Comparison of methods and inoculum source. J. Dairy Sci., 83: 2289-2294.

M c All ister T.A., Phillippe C., R od e L.M., Cheng K.J. (1993). Effect of the protein matrix on the digestion of cereal grains by ruminal microorganisms. J. Anim. Sci., 71: 205-212.

M e n k e H.H., S te in g a s s H. (1988). Estimation of the energetic feed value obtained from chemical analysis and in vitro gas production using rumen fluid. Anim. Res. Develop., 28: 7-55.

Merten s D.R. (2002). Gravimetric determination of amylase-treated neutral detergent fiber in feeds with refluxing in beakers or crucibles: Collaborative Study. J. AOAC Int., 85: 1217-1240. 
M i c e k P. (2008). Nutritional usefulness to ruminants of grain of Polish cereal species and cultivars (in Polish). Scientific papers of University of Agriculture in Krakow. Habilitation thesis, 326: $1-127$.

Mills J.A.N., France J., Dijkstra J. (1999). A review of starch digestion in the lactating dairy cow and proposals for a mechanistic model. 2. Postruminal starch digestion and small intestinal glucose absorption. J. Anim. Feed Sci., 8: 451-481.

N i k o k y ri is P.N., K a n d y li s K. (1997). Feed protein fractions in various solvents of ruminant feedstuffs. J. Sci. Food Agric., 75: 198-204.

NRC (2001). National Research Council. Nutrient Requirements of Dairy Cattle. 7th rev. ed., National Academy Press, Washington, DC.

O ffner A., S a u vant D. (2004). Prediction of in vivo starch digestion in cattle from in situ data. Anim. Feed Sci. Tech., 111: 41-56.

O w e n s F.N., Z in n R.A., K i m Y.K. (1986). Limits to starch digestion in the ruminant small intestine. J. Anim. Sci., 63: 1634-1648.

Ø r s k o v E.R. (1986). Starch digestion and utilization in ruminants. J. Anim. Sci., 63: 1624-1633.

Ørskov E.R., Mc Donald P. (1979). The estimation of protein degradability in the rumen from incubation measurements weighted according to rate of passage. J. Agric. Sci., 92: 499-503.

P e tr J. (2005). Yield potential of rye, hybrid and population varieties in ecological and intensive cultivation. Sci. Agric. Bohem., 36: 41-48.

Peyraud J.L., Ge nest - Ru lquin Ch., Verité R. (1988). Mesure de la digestion de l'azote des aliments dans l'intestin des ruminants par la technique des sachets mobiles. 1. Evaluation de la quantité de matières azotées indigestibles en sachet des principaux aliments. Reprod. Nutr. Dev., 28: 129-130.

Philippe a u C., M i chalet - D or e a u B. (1998). Influence of genotype and ensiling of corn grain on in situ degradation of starch in the rumen. J. Dairy Sci., 81: 2178-2184.

Philippeau C., Le Deschault de Monredon F., Michalet-Doreau B. (1999). Relationship between ruminal starch degradation and the physical characteristics of corn grain. J. Anim. Sci., 77: 238-243.

Pla izi er J.C., Kra us e D.O., G o zho G.N., M c Bride B.W. (2009). Subacute ruminal acidosis in dairy cows: the physiological causes, incidence and consequences. Vet. J., 176: 21-31.

Rémond D., Cabrera-Estrada J.I., Champion M., Chauveau B., Coudure R., Ponc e t C. (2004). Effect of corn particle size on site and extent of starch digestion in lactating dairy cows. J. Dairy Sci., 87: 1389-1399.

Roberts on J.B., Van S o e st P.J. (1981). The detergent system analysis and its application to human foods. In: The analysis of dietary fiber in food, J. Theander (ed.). Dekker INC, pp. 123-157.

Rowe J.B., Choct M., P e thi ck D.W. (1999). Processing cereal grains for animal feeding. Aust. J. Agric. Res., 50: 721-736.

$\mathrm{S}$ a u v a n t D. (1997). Conséquences digestives et zootechniques des variations de la vitesse de digestion de l'amidon chez les ruminants. INRA Prod. Anim., 10: 287-300.

Seifried N., Steingass H., Schipprack W., Rodehutscord M. (2016). Variation in ruminal in situ degradation of crude protein and starch from maize grains compared to in vitro gas production kinetics and physical and chemical characteristics. Arch. Anim. Nutr., 70: 333-349.

Svihus B., Uhlen A.K., Harstad O.M. (2005). Effect of starch granule structure, associated components and processing on nutritive value of cereal starch: A review. Anim. Feed Sci. Tech., 122: 303-320.

Tagli ap i etra F., Cattani M., Hansen H., Hindri chsen I., B a iloni L., S chiavon S. (2011). Metabolizable energy content of feeds based on 24 or $48 \mathrm{~h}$ in situ NDF digestibility and on in vitro $24 \mathrm{~h}$ gas production methods. Anim. Feed Sci. Tech., 170: 182-191.

Toth i R., L und P., We is bje rg M.R., Hvelplund T. (2003). Effect of expander processing on fractional rate of maize and barley starch degradation in the rumen of dairy cows estimated using rumen evacuation and in situ techniques. Anim. Feed Sci. Tech., 104: 71-94.

Wang M., Ji ang J., Tan Z.L., Tang S.X., S u n Z.H., H a n X.F. (2009). In situ ruminal crude protein and starch degradation of three classes of feedstuffs in goats. J. Appl. Anim. Res., 36: $23-28$. 
W o o d s V.B., M o l o n e y A.P., O ' M a r a F.P.O. (2003). The nutritive value of concentrate feedstuffs for ruminant animals: Part II: In situ ruminal degradability of crude protein. Anim. Feed Sci. Tech., 110: $131-143$.

Received: 17 VII 2019

Accepted: 18 II 2020 